\title{
Assessing the sources of uncertainty associated with the calculation of rainfall kinetic energy and erosivity - application to the Upper Llobregat Basin, NE Spain
}

\author{
G. Catari ${ }^{1,2}$, J. Latron ${ }^{1}$, and F. Gallart ${ }^{1}$ \\ ${ }^{1}$ Institute of Environmental Assessment and Water Research (IDAEA), CSIC, Jordi Girona, 18-26, 08034 Barcelona, Spain \\ ${ }^{2}$ Institute of Environmental Sciences and Technology (ICTA), Autonomous University of Barcelona (UAB), \\ 08193 Bellaterra/Barcelona, Spain
}

Received: 20 May 2010 - Published in Hydrol. Earth Syst. Sci. Discuss.: 14 June 2010

Revised: 30 November 2010 - Accepted: 19 February 2011 - Published: 1 March 2011

\begin{abstract}
The diverse sources of uncertainty associated with the calculation of rainfall kinetic energy and rainfall erosivity, calculated from precipitation data, were investigated at a range of temporal and spatial scales in a mountainous river basin $\left(504 \mathrm{~km}^{2}\right)$ in the south-eastern Pyrenees. The sources of uncertainty analysed included both methodological and local sources of uncertainty and were (i) tipping-bucket rainfall gauge instrumental errors, (ii) the efficiency of the customary equation used to derive rainfall kinetic energy from intensity, (iii) the efficiency of the regressions obtained between daily precipitation and rainfall erosivity, (iv) the temporal variability of annual rainfall erosivity values, and the spatial variability of (v) annual rainfall erosivity values and (vi) long-term erosivity values. The differentiation between systematic (accuracy) and random (precision) errors was taken into account in diverse steps of the analysis. The results showed that the uncertainty associated with the calculation of rainfall kinetic energy from rainfall intensity at the event and station scales was as high as $30 \%$, because of insufficient information on rainfall drop size distribution. This methodological limitation must be taken into account for experimental or modelling purposes when rainfall kinetic energy is derived solely from rainfall intensity data. For longer temporal scales, the relevance of this source of uncertainty remained high if low variability in the types of rain was supposed. Temporal variability of precipitation at wider spatial scales was the main source of uncertainty when rainfall erosivity was calculated on an annual basis, whereas the uncertainty associated with
\end{abstract}

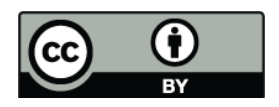

Correspondence to: F. Gallart (francesc.gallart@idaea.csic.es) long-term erosivity was rather low and less important than the uncertainty associated with other model factors such as those in the RUSLE, when operationally used for long-term soil erosion modelling.

\section{Introduction}

Raindrop impact is the main cause of interrill soil erosion. Rainfall kinetic energy or some surrogate or derivative is therefore a variable used by nearly all soil erosion models. In particular, Wischmeier and Smith (1959), on the basis of rill and interrill erosion measurements in erosion plots, defined rainfall erosivity as a product of event rainfall kinetic energy and depth. Under experimental conditions, rainfall kinetic energy is obtained from rainfall intensity and raindrop size distribution, normally measured with the flour tray (Laws and Parsons, 1943) or the dyed filter paper (Marshall and Palmer, 1948) methods, although on-site continuous electromechanical (Joss and Waldvogel, 1967), optical or microwave disdrometers and remote short radiofrequency wave attenuation methods are increasingly used. Nevertheless, since information on raindrop size distribution is usually not available at the level of weather data, erosion models make use of some procedure to obtain information on rainfall kinetic energy from intensity or depth measurements. At the scale of the event, rainfall kinetic energy is commonly estimated from sub-hourly measurements of rainfall intensity with a non-linear equation (Kinnell, 1973) that relates rainfall intensity and the specific kinetic energy of short rainfall intervals. At larger and longer-term scales, relationships between (daily, seasonal or annual) precipitation depth and

Published by Copernicus Publications on behalf of the European Geosciences Union. 
rainfall erosivity are usually obtained and applied for longterm and mesoscale or regional assessment, by precipitation data from regular networks.

In spite of the warning issued by Parsons and Gadian (2000), the uncertainty associated with the estimation of rainfall kinetic energy or erosivity is commonly taken as negligible when compared to the uncertainty associated with the other parameters of soil erosion models (e.g. Hartcher and Post, 2005; Biesemans et al., 2000), or is only analysed in terms of spatial variability when assessed for large areas (e.g. Wang et al., 2001; Falk et al., 2010). However, the increasing use of soil erosion models and the rising concern about soil erosion predictions under Global Change scenarios justify the need for an assessment of the uncertainties associated with the calculation of this primary cause of soil erosion.

The purpose of this paper is to analyse the diverse sources of uncertainty associated with the calculation of rainfall kinetic energy and erosivity when obtained from precipitation data for a range of temporal and spatial scales, from the event at the station scale to the long-term mesoscale area (here the Upper Llobregat basin, $504 \mathrm{~km}^{2}$ ), for applying a soil erosion model such as the RUSLE (Foster, 2004). This paper follows on from a previous paper (Catari and Gallart, 2010), in which the rainfall erosivity $R$ factor was calculated for this area. This previous study also included an analysis of spatial distribution and a simplified approach for estimating the uncertainty introduced when erosivity was upscaled from the event to longer periods. After this study, it became apparent that other sources of uncertainty in the diverse steps, particularly the calculation of rainfall kinetic energy from precipitation data at the event scale (Parsons and Gadian, 2000), had to be taken into account if the uncertainties associated with the estimation of rainfall kinetic energy and erosivity were to be appraised comprehensively. To achieve this, available datasets of the relationship between rainfall intensity and kinetic energy from different locations worldwide were analysed and used to develop an equation describing the uncertainty of this relationship. Finally, six sources of uncertainty were identified and assessed by statistical methods that are unsophisticated, but are designed to cover the entire expectable span.

This work is therefore of intended interest for any researcher using rainfall kinetic energy or erosivity at diverse scales, from the erosion plot studies at the event scale to the regional long-term operational erosion modelling. The methods used may hopefully be extended for application to other studies where spatial and temporal upscaling of information is needed.

\section{Materials and methods}

The overall design follows a procedure for obtaining a longterm estimate of rainfall erosivity at the basin scale. Rainfall erosivity $R$ factor is a widely used long-term estimate of the annual rainfall capacity to produce soil interrill and rill erosion in an area, commonly obtained with the equation proposed by Wischmeier and Smith (1978):

$R=\frac{1}{n} \sum_{j=1}^{n} \sum_{k=1}^{m}\left(E I_{30}\right)_{k}$

where $k$ represents single rainstorms, $E$ is the total kinetic energy of rainfall during a storm, $I_{30}$ represents the maximum storm rainfall intensity in a period of $30 \mathrm{~min}, m$ represents the number of storms in a year and $j$ represents the year within the record of $n$ years. Units for storm erosivity $E I_{30}$ are usually $\mathrm{MJ} \mathrm{mm} \mathrm{ha}{ }^{-1}$ and for $R$ are usually $\mathrm{MJ} \mathrm{mm} \mathrm{ha}{ }^{-1} \mathrm{yr}^{-1}$. In this study, events were defined as those having precipitation depth of $12.5 \mathrm{~mm}$ or higher (following Foster, 2004) and the criterion for separating rainfall events was a daily one (available resolution of the wider precipitation network).

As described below in more detail, the event rainfall erosivity $\left(E I_{30}\right)$ of a set of 211 rainstorms was calculated by subhourly precipitation records from one tipping-bucket rainfall recorder. Then a relationship between daily precipitation and rainfall erosivity was derived from these data and applied to the daily precipitation records in a set of stations in order to obtain estimates of daily rainfall erosivity. This made it possible to apply Eq. (1) to this set of rainfall stations with only daily data. Subsequently, the annual erosivity values from the rainfall stations were aggregated in time and space to obtain the erosivity for the study area.

The diverse steps analysed were therefore the following ones: (i) rainfall depth and intensity measurement using a tipping-bucket rain gauge connected to a data-logger, (ii) calculation of rainfall kinetic energy from rainfall depth and intensity using a non-linear equation, (iii) upscaling from event rainfall erosivity values using sub-hourly precipitation to daily values using daily precipitation records, (iv) temporal upscaling from annual rainfall erosivity to long-term values, (v) spatial upscaling from annual station rainfall erosivities to basin values and (vi) spatial upscaling from station long-term erosivities to basin values.

The uncertainty introduced at each of these steps was calculated separately and subsequently handled by error transmission formulas. In some steps it was necessary to decide whether the errors were due to spurious random deviations (precision errors), compensated for by subsequent values and partly cancelled out by them, or they were systematic deviations (accuracy errors) that were not compensated for by subsequent values. Standard deviation and standard error of the mean were commonly used to express the uncertainty of the values, although the coefficient of variation and $90 \%$ 


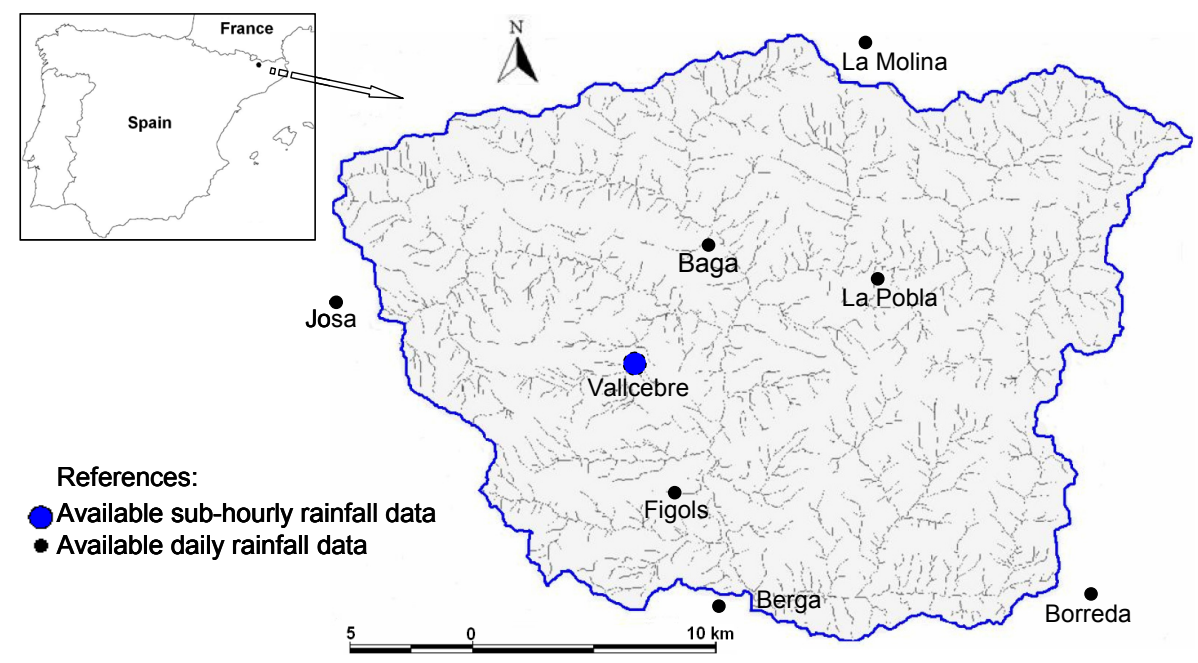

Fig. 1. Study area and location of rainfall stations.

confidence bounds were used in some cases for easier understanding.

\subsection{Study area and source data}

The study area is located in the Pyrenees, NE Spain, at the headwaters of the Llobregat River basin (Fig. 1). This area of $504 \mathrm{~km}^{2}$ consists of a mountainous rangeland with a highly contrasted relief. Mean elevation is $1271 \mathrm{~m}$, varying between $627 \mathrm{~m}$ and $2540 \mathrm{~m}$ a.s.1., and the average slope is $24^{\circ}$ (Catari, 2010). The climate is humid Mediterranean with a mean annual precipitation of $862 \pm 206 \mathrm{~mm}$, with a mean of 90 rainy days. The rainiest seasons are autumn and spring; and winter is the season with least precipitation. In summer, convective storms may provide significant precipitation input and the highest rainfall intensities (Latron et al., 2010); the mean annual temperature is $9.1^{\circ} \mathrm{C}$ (Delgado, 2006; Gallart et al., 2002).

A sub-hourly precipitation dataset from the Vallcebre research basins, located in the central part of the study area and managed by the Surface Hydrology and Erosion Research Group at IDAEA (CSIC), was used for obtaining rainfall kinetic energy and erosivity at the event scale $\left(E I_{30}\right)$. No other data series of similar time resolution is available in the area. The data set used comprises 211 rainfall events collected between January 1994 and December 2005, with depths higher than $12.5 \mathrm{~mm}$ or 15 -min intensity greater than $6.25 \mathrm{~mm} \mathrm{~h}^{-1}$. Although snow falls seldom occurred, the rain recorder was not equipped with any heating system; as winter is the season with the least precipitation depth and winter precipitation had low erosivity (see below), snow events were not excluded from the analysis.

Rainfall datasets at daily resolution were available from seven additional weather stations, operated by the Spanish
Table 1. Location of weather stations in or near the headwaters of the Llobregat River basin.

\begin{tabular}{llllr}
\hline Weather station & INM Code & UTM $(x)$ & UTM $(y)$ & Altitude m a.s.l. \\
\hline La Molina & 585 & 412463 & 4687479 & 1680 \\
Josa Tuixén & $632 \mathrm{o}$ & 381765 & 4676545 & 1184 \\
Vallcebre & $84 \mathrm{i}$ & 402375 & 4673051 & 1133 \\
Borredà & 99 & 421212 & 4665411 & 845 \\
La Pobla & $78 \mathrm{u}$ & 413296 & 4677011 & 808 \\
Bagà & 82 & 406006 & 4678709 & 795 \\
Fígols & $85 \mathrm{a}$ & 405773 & 4669858 & 754 \\
Berga & $92 \mathrm{c}$ & 404520 & 4662070 & 664 \\
\hline
\end{tabular}

Source: INM (2004) and Delgado (2006)

National Meteorological Institute (INM, 2004). Four of these stations are within the limits of the study area and three nearby; they are located at a wide range of altitudes and are fairly equidistant from each other. The coordinates and altitudes of the stations are shown in Table 1.

\subsection{Rainfall depth and intensity measurements}

Precipitation at the Vallcebre station was measured with an Institut Analític AWP-P tipping bucket stainless-steel rain recorder, with a nominal capacity of $0.2 \mathrm{~mm}$ per tip. The time at which each movement of the bucket occurred was recorded at a resolution of $1 \mathrm{~s}$ by an event-recording data logger (Chatalog, Orion Group). Calibration from tips to rainfall depths employed the approach proposed by Calder and Kidd (1978). This calibration improves the accuracy of the measurement of high-intensity values by taking into account that a certain amount of rain water may be lost to the measurement when it falls into a bucket already containing its nominal capacity and movement starts (i.e. during a "dead time"). The rainfall 
Table 2. Sources of data used for the analysis of the uncertainty associated with the Kinnell (1981) equation.

\begin{tabular}{lllrl}
\hline Site & Intensities $\left(\mathrm{mm} \mathrm{h}^{-1}\right)$ & $\begin{array}{l}\text { Number of } \\
\text { means }\end{array}$ & $\begin{array}{r}\text { Number of } \\
\text { observations }\end{array}$ & References \\
\hline Miami, Florida & $1.83-200$ & 10 & 200 & Kinnell (1981) based on Kinnell (1973) \\
Miami, Florida & $18.5-228.6$ & n.a. & 30 & Kinnell (1981) based on Hudson (1961) \\
Zimbabwe & $18.5-228.6$ & n.a. & 19 & Kinnell (1981) based on Hudson (1961) \\
Holly Springs, Mississippi & $0-257$ & n.a. & 315 & McGregor and Mutchler (1976) \\
Gunnedah, Australia & $0-150$ & 18 & 12894 & Rosewell (1986) \\
Brisbane, Australia & $0-160$ & 19 & 6360 & Rosewell (1986) \\
\hline
\end{tabular}

intensity during a time period $t$ (hours) was obtained by using Eq. (2):

$$
I=\frac{n \cdot V_{0}}{t-\left(t_{0} \cdot n\right)}
$$

where $I$ is the measured intensity $\left(\mathrm{mm} \mathrm{h}^{-1}\right), n$ is the number of tips observed during every measurement period, $V_{0}$ is the nominal capacity of the tipping bucket at null intensity ( $\mathrm{mm})$, $t$ is the time span (hours) and $t_{0}$ is the "dead time" when rainfall is not measured (hours per tip). Parameters $V_{0}$ and $t_{0}$, as well as the residuals of this relationship, were obtained by calibration covering a wide span of simulated rainfall intensities.

The results obtained with this approach were compared to these obtained with the customary approach that uses a fixed bucket capacity. The difference was considered a systematic source of error, as the fixed bucket capacity approach means an overestimation of rainfall depth for low-intensity events and an underestimation for high-intensity ones. Subsequently, the analysis of local random errors in the measurement of precipitation proposed by Ciach (2003) was applied to calculate the random errors in the determination of rainfall erosivity at the event scale, using the common parameters of a systematic time interval of $30 \mathrm{~min}$ and a tip-counting procedure.

Precipitation at the INM stations was manually measured every day at 08:00 a.m. LT, using graduated cylinders, and counted for the preceding day. The possible errors in such data were not assessed due to the lack of an adequate dataset, though they may be relevant. Systematic errors in rain measurements by standard rain gauges may be as high as $15 \%$, mainly due to the role of wind and evaporation, but decreases to about 5\% during heavy rainfalls (Sevruk, 1987).

\subsection{Deriving rainfall kinetic energy from rainfall depth/intensity records}

Rainfall kinetic energy is used by most erosion models for assessing the capacity of rainfall to produce erosion. As usual in the application studies, rainfall kinetic energy was derived from an empirical equation that allows the specific kinetic energy per unit of rainfall depth to be obtained from the instantaneous rainfall intensity. More recent studies proposed the alternative use of equations using specific kinetic energy per unit time (Salles et al., 2002), but these equations are still of limited practical application and may be related to the classic ones through rain intensity. Currently, the most commonly accepted kinetic energy-intensity relationship is the one with two terms, a fixed value and a negative exponential of the intensity (Eq. 3), proposed by Kinnell (1981):

$E_{\mathrm{kd}}=e_{\max }[1-a \cdot \exp (-b \cdot I)]$

where $E_{\mathrm{kd}}$ is the specific rainfall kinetic energy per rainfall depth, $e_{\max }$ is the maximum specific kinetic energy, $I$ is rainfall intensity, and $a$ and $b$ are constants, experimentally obtained using measurements of the distribution of rainfall drop sizes. Diverse values for these parameters have been proposed by several authors from measurements at several sites and under a range of rainfall conditions (McGregor and Mutchler, 1976; Rosewell, 1986; Brown and Foster, 1987). According to the user's guide of the RUSLE2 model (Foster, 2004), the kinetic energy of rainfall was calculated from Eq. (4), which includes the modification suggested by McGregor et al. (1995):

$E_{\mathrm{kd}}=0.29[1-0.72 \exp (-0.082 I)]$

where $E_{\mathrm{kd}}$ is in $\mathrm{MJ} \mathrm{ha}^{-1} \mathrm{~mm}^{-1}$ and $I$ is in $\mathrm{mm} \mathrm{h}^{-1}$.

Diverse published graphs of the relationships observed between $E_{\mathrm{kd}}$ and the intensity of short rain intervals, from diverse sites around the world including various types of rain, were investigated (summarised in Table 2). For this, the original graphs were digitized and the outcome data were used to derive the scattering of observations around the means.

The scattering of the kinetic energy - rainfall intensity relationship of instantaneous rainfall intervals, for such a 
general dataset, is low at high-intensity values owing to the dynamic equilibrium of raindrop distribution (Zawadzki and Antonio, 1988; Assouline and Mualem, 1989), but it increases for decreasing intensities because raindrop distribution depends on the diverse mechanisms of drop formation or "type of rain" (e.g. Salles et al., 2002; van Dijk et al., 2002) and may even suffer dramatic changes within storms (Sempere-Torres et al., 1994). The decrease in the dispersion of the specific kinetic energy of short rainfall intervals for increasing rainfall intensity may appear unclear if several of the published specific kinetic energy - rainfall intensity equations are compared (e.g. Salles et al., 2002; Fig. 2a), but this has to be attributed to the varied quality of the equations for high-intensity conditions given the diverse ranges of rainfall intensities used to fit these equations (Salles et al., 2002; Table 1).

An empirical relationship between the dispersion of specific kinetic energy and intensity was therefore sought by re-constructing the data shown in the graphs. Assuming a log-normal distribution of the point measurements of specific kinetic energy $E_{\mathrm{kd}}$, the variances of the logarithms of these measurements were derived from the information given in the graphs and averaged for narrow ranges of rainfall intensity. The log-normal distribution was selected because most of the graphs of the observed specific kinetic energy showed clear asymmetry of the values around the mean, and this type of distribution is physically reasonable for 'size' variables when the low values are limited to 0 . Then, a non-linear equation was fitted to describe the relationship between intensity and dispersion. It is worth mentioning that, when we used this latter equation to derive the scatter of the kinetic energy from the value given by Eq. (4) for every time step of the storms, the scatter was taken as systematic (accuracy error) because it is primarily a bias from the mean line, owing to the (unknown) type of storm analysed.

The question then arises whether, when event rainfall erosivity $E I_{30}$ estimates are to be accumulated to obtain the annual totals, it can be assumed that the diverse events during the year belong to different types of precipitation and thus the errors may be considered random (precision) ones and are partly cancelled out; or whether the errors should still be seen as systematic (accuracy) ones because there is not sufficient variability in types of rain. As this is mainly a methodological analysis, both possibilities were considered. Thus, two different estimates of the uncertainties derived from the use of Eq. (3) were obtained: (i) systematic errors during the events and systematic errors between the events, and (ii) systematic errors during the events and random errors between the events.

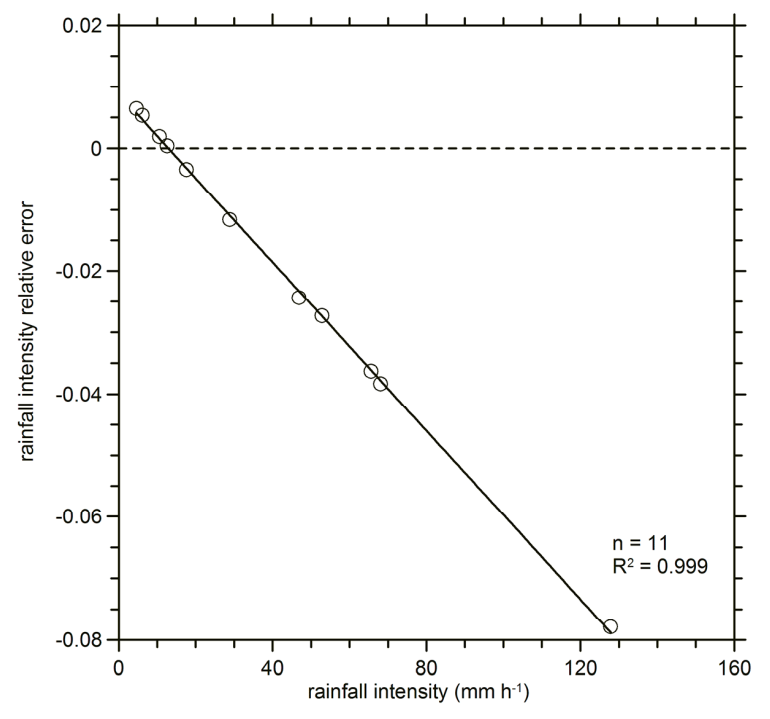

Fig. 2. Relative errors in the determination of rainfall depth (and intensity) when a fixed volume of the rain recorder tipping bucket is considered.

\subsection{Upscaling rainfall erosivity from sub-hourly to daily values}

Sub-hourly rainfall data for obtaining event rainfall erosivity are not always readily available; instead, downscaling approaches, such as those for daily, monthly or annual resolution, are used. For instance, de Santos Loureiro and Azevedo Coutinho (2001) calculated the rainfall-runoff erosivity index by using monthly data in Portugal; in Italy, Diodato (2004) developed a method for using annual data, obtaining satisfactory results.

The relationships between daily rainfall erosivity (dependent variable) and daily rainfall depth (predictor) for the station with sub-hourly data (Vallcebre) were developed. Then these relationships were applied to stations with only daily resolution (Upper Llobregat basin). After the first trials, as it was clear that the relationship between rainfall depth and erosivity varied seasonally, two different regressions, one for summer and one for the rest of the seasons, were computed.

The uncertainty associated with the use of these regressions was obtained from the analysis of the residuals and through error propagation formulas.

\subsection{Temporal and spatial aggregation}

The annual rainfall erosivity (Eq. 1) was calculated for every rainfall station by cumulating the $m$ storm (daily) erosivities occurring in that year. The basin-scale erosivity for every year was obtained using the Thiessen polygon method (Thiessen, 1911) for weighing the annual erosivity values obtained at the stations. This allowed the analysis of the temporal and spatial variability of erosivity values. The contribution of every station to spatial variability was assessed by 
calculating the variance of the areal average on the basis of the Thiessen-weighted contributions from the pluviometric stations. The Thiessen polygons method was selected to integrate the station values spatially, due to its greater simplicity in obtaining both the variable value and its uncertainty. The analysis of the uncertainty introduced by areal interpolation methods is beyond the scope of this paper: readers may refer to other recent studies specifically addressing this issue (e.g. Moulin et al., 2009).

The uncertainties of the final $R$ value due to temporal and spatial variability were obtained as the standard errors of the mean. Nevertheless, in order to consider applications in which rainfall erosivity might be used at the annual scale, so as to estimate annual soil erosion hazard, the standard deviation from annual erosivity was also considered.

\section{Results and discussion}

The average annual $R$ factor value for the Upper Llobregat basin was $1986 \pm 532 \mathrm{MJ} \mathrm{mm} \mathrm{ha}^{-1} \mathrm{yr}^{-1}$ (90\% uncertainty bounds). This value is between values estimated for the NE of Spain, such as $1400 \mathrm{MJ} \mathrm{mm} \mathrm{ha}^{-1} \mathrm{yr}^{-1}$ given by Usón and Ramos (2001) for a single year (1996) and $2628 \mathrm{MJ} \mathrm{mm} \mathrm{ha}^{-1} \mathrm{yr}^{-1}$ given by MMA (2004). At Vallcebre, summer precipitation contributed to $58 \%$ of annual rainfall erosivity, though it accounted for only about $26 \%$ of the annual rainfall depth.

The analysis of the uncertainty associated with each of the steps is explained separately in the following sub-sections.

\subsection{Rain depth and intensity measurements}

When a fixed volume of the tipping bucket of the rain recorded was held, the volume was optimised to obtain the best estimate of the total rainfall depth. The error analysis showed a bias of the depth and intensity estimates negatively proportional to the rainfall intensity, which resulted in a slight overestimation of precipitation for low intensities and a fair underestimation for high intensities (Fig. 2). Subsequently, when the analysis was applied to the precipitation recorded at Vallcebre, the higher precipitation intensity in summer meant a slight underestimation of both rainfall kinetic energy and erosivity ( -1.3 and $-1.7 \%$ respectively), whereas for the rest of the seasons, there was a slighter overestimation of both values $(0.12 \%)$. These low error values led us to rule out analysis of this source of error in the subsequent analyses, though it is worth mentioning that the underestimation of volumes during heavy-intensity events may be of some relevance.

Errors in the calculation of rainfall erosivity at the event scale due to the random local errors in the tipping-bucket rain gauges, in terms of root mean squares, were nearly proportional to the rainfall depths. The slope of the relationship was a little higher for the summer events than for the events

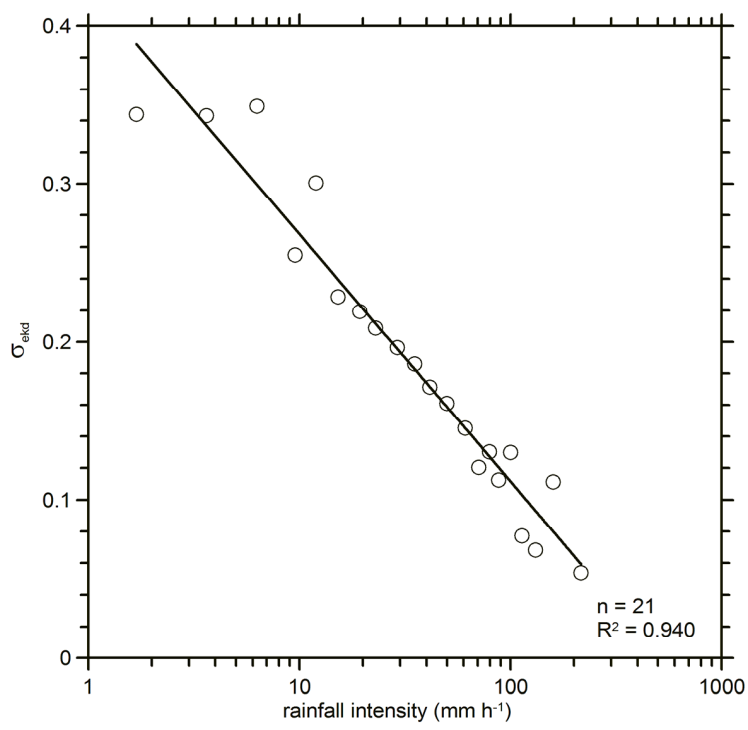

Fig. 3. Relationship between the standard deviation of the natural logarithm of the specific kinetic energy and the rainfall intensity obtained from the graphs listed in Table 2.

in the other seasons. Nevertheless, the relative errors (variation coefficients) were on average less than $7 \%$ for summer events and $10 \%$ for the rest of the year, with trends decreasing with event depths. When these errors were propagated to the long-term $R$ value, the resulting coefficients of variation were $1.2 \%$ if random compensation of the errors was assumed and $4.5 \%$ if a persistent bias of the rain gauge is involved. As only one source of errors was considered in the determination of rainfall volumes and intensities, the latter value was retained for the overall analysis.

\subsection{Rainfall kinetic energy calculation}

The relationship between the dispersion of specific kinetic energy and rainfall intensity when the Kinnell (1981) expression is used (Eq. 3 and Table 2) was fitted with a logarithmic equation, explaining $94 \%$ of the original gross variance (Eq. 5 and Fig. 3):

$\sigma_{\mathrm{ekd}}=-0.0679 \cdot \operatorname{Ln}(I)+0.4245$

where $\sigma_{\mathrm{ekd}}$ is the standard deviation of the natural logarithm of the specific rainfall kinetic energy $E_{\mathrm{kd}}$, which takes values numerically close to the values of the variation coefficient of the physical variable, and $I$ is rainfall intensity $\left(\mathrm{mm} \mathrm{h}^{-1}\right)$. This equation affords a good fit to the data for all the measured ranges of short rainfall intervals and gives physically plausible positive results for rainfall intensities up to $519 \mathrm{~mm} \mathrm{~h}^{-1}$, a value much beyond the observed range.

This relationship is consistent with the physical grounds of rainfall kinetic energy mentioned in Materials and Methods. Relative dispersion is minimal for high-intensity rainfalls 
which have fairly similar drop-size distribution functions owing to the dynamic equilibrium of drops, whereas the variability of drop-size distribution functions increases with decreasing rainfall intensity owing to the increasing diversity of 'types of rain' included in the analysis.

As is commonly done in operational use, Eq. (3) was applied to the sub-hourly precipitation data in order to obtain the event rainfall kinetic energy and its erosivity, regardless of the type of rain concerned. Consequently, the dispersion obtained from Eq. (5) was used as "systematic error", the squared errors being accumulated for every time step and rainfall depth, without allowing the compensation usual in random errors.

When this analysis was applied to the rainfall events recorded at Vallcebre, the results showed that the eventaveraged values of both $\sigma_{\text {ekd }}$ and the coefficient of variation of $K e$ had mean values of 0.26 for summer events and 0.31 for the rest of the seasons. The difference, statistically significant, was attributed to the higher intensity of summer events. At the annual scale, the uncertainty associated with the determination of kinetic energy and rainfall erosivity depended on the relative weight of summer events and, if a random occurrence of types of rain is assumed, on the total number of events.

Figure 4 shows the rainfall kinetic energy $(K e)$ values and the corresponding $90 \%$ confidence bounds obtained for a random sample of 90 rainstorms recorded at Vallcebre, using Eqs. (3) and (5). This graph shows a relevant range of error of the estimates of $K e$ and the fair seasonal differences. This error could be reduced either by obtaining direct measurements of raindrop size/energy during storms, as recommended by Parsons and Gadian (2000), or by using diverse Kinnell-type equations fitted to the corresponding types of rainstorms, along with a correct identification of the storm type in order to apply the right equation.

The uncertainty (standard error of the mean) of the longterm total $R$ value attributed to the calculation of the rainfall kinetic energy was $206 \mathrm{MJ} \mathrm{mm} \mathrm{ha}{ }^{-1} \mathrm{yr}^{-1}(10.7 \%$ of the $R$ value), when the rigorous criterion of event systematic error (invariance of types of rain) was applied; and $43 \mathrm{MJ} \mathrm{mm} \mathrm{ha}{ }^{-1} \mathrm{yr}^{-1}$ (2.2\% of the $R$ value), when the more relaxing criterion of event random error (variability of types of rain between the events) was applied.

\subsection{Daily values of rainfall erosivity}

In Vallcebre, the rainy seasons are usually autumn and spring. However, during the summer short intense convective storms provide significant rainfall amounts (Latron et al., 2003). Therefore, the relationships between rainfall depth and erosivity were analysed separately (Fig. 5 and Eqs. 6 and 7) for the summer and the rest of the seasons. An ANOVA test indicated that residual variance was

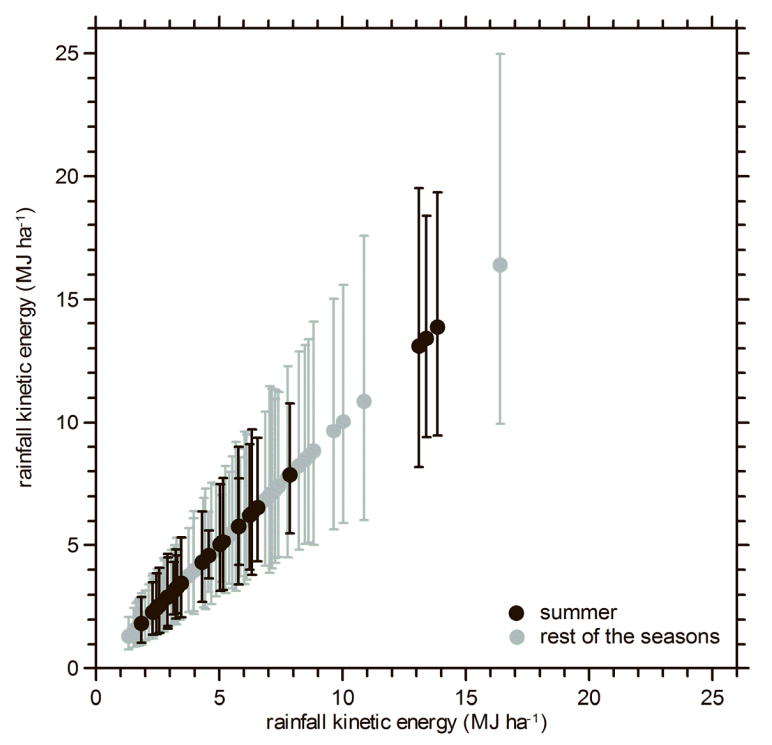

Fig. 4. 90\% uncertainty bounds for a set of estimates of event rainfall kinetic energy at Vallcebre, obtained from rainfall records using Eqs. (4) and (5).

significantly lower when two equations were used instead of one $(F=310.4, p<0.05)$.

$\begin{array}{lll}E_{\mathrm{s}}=-98.52+10.34 P & R^{2}=0.55 & n=61 \\ E_{\mathrm{w}}=-23.48+2.54 P & R^{2}=0.60 & n=150\end{array}$

where $E_{\mathrm{S}}$ and $E_{\mathrm{w}}$ are the daily values of storm erosivity $\left(E I_{30}, \mathrm{MJ} \mathrm{mm} \mathrm{ha}{ }^{-1} \mathrm{~h}^{-1}\right)$ for summer and the rest of seasons, respectively, and $P$ is the value of daily precipitation $(\mathrm{mm})$. The parameters in Eqs. (6) and (7) were considered fixed and the uncertainty of the estimates was derived from the dispersion of the residuals.

The absolute residuals of the daily erosivity $\left(E I_{30}\right)$ values estimated by means of Eqs. (3) and (4) were roughly proportional to the daily rainfall depth. The corresponding factors were 3.1 for summer events and 0.87 for the rest of the seasons.

The uncertainty of the long-term total $R$ value attributed to the simplification from sub-hourly to daily precipitation data, assuming that there was a random compensation of the errors, was $58 \mathrm{MJ} \mathrm{mm} \mathrm{ha}^{-1} \mathrm{yr}^{-1}$ ( $3 \%$ of the $R$ value) expressed in terms of the standard error of the mean value. If a single annual equation instead of two seasonal equations was used, this source of uncertainty would be increased to a value of about $7.8 \%$ of the mean $R$ value.

\subsection{Spatial and temporal averaging}

Table 3 shows the annual rainfall erosivity obtained for the stations and years analysed. Annual erosivity values obtained at the stations showed large spatial variability, which clearly 
Table 3. Annual rainfall erosivity values obtained at the stations ( $\mathrm{MJ} \mathrm{mm} \mathrm{ha} \mathrm{mr}^{-1} \mathrm{yr}^{-1}$.

\begin{tabular}{lrccrrrrrrr}
\hline Year & Berga & Figols & Borreda & Baga & Pobla & Vallcebre & Molina & Josa & average & var. coeff. \\
\hline 1991 & 1810 & 2259 & 1785 & 1130 & 2657 & 1368 & 1494 & 1034 & 1865 & $31 \%$ \\
1992 & 2135 & 2513 & 3668 & 3544 & 4426 & 2592 & 3304 & 4016 & 3462 & $20 \%$ \\
1993 & 925 & 1479 & 1670 & 805 & 1298 & 1280 & 1270 & 1031 & 1231 & $21 \%$ \\
1994 & 1201 & 2323 & 1768 & 1294 & 3066 & 2115 & 2647 & 3259 & 2270 & $30 \%$ \\
1995 & 2913 & 3968 & 3547 & 1401 & 2115 & 2123 & 1850 & 1500 & 2366 & $39 \%$ \\
1996 & 1589 & 3464 & 2523 & 1729 & 1910 & 2131 & 3025 & 3200 & 2427 & $28 \%$ \\
1997 & 2464 & 2914 & 2564 & 1106 & 1592 & 1786 & 2871 & 3739 & 2118 & $35 \%$ \\
1998 & 1100 & 3232 & 1508 & 651 & 931 & 764 & 1085 & 1139 & 1349 & $66 \%$ \\
1999 & 2466 & 5240 & 3137 & 1600 & 2285 & 1525 & 2815 & 2581 & 2813 & $43 \%$ \\
2000 & 965 & 1322 & 1261 & 1511 & 1128 & 1297 & 1358 & 2207 & 1308 & $13 \%$ \\
2001 & 1375 & 1063 & 2409 & 1171 & 1538 & 1179 & 1278 & 924 & 1370 & $25 \%$ \\
2002 & 2437 & 1853 & 2657 & 1303 & 1653 & 1320 & 1616 & 1542 & 1703 & $22 \%$ \\
2003 & 1941 & 1536 & 1381 & 1390 & 1462 & 1155 & 1810 & 1537 & 1536 & $12 \%$ \\
\hline average & 1794 & 2551 & 2298 & 1434 & 2005 & 1587 & 2033 & 2131 & 1986 & $35 \%$ \\
var. coeff. & $37 \%$ & $47 \%$ & $35 \%$ & $49 \%$ & $47 \%$ & $33 \%$ & $38 \%$ & $52 \%$ & $44 \%$ & \\
\hline
\end{tabular}
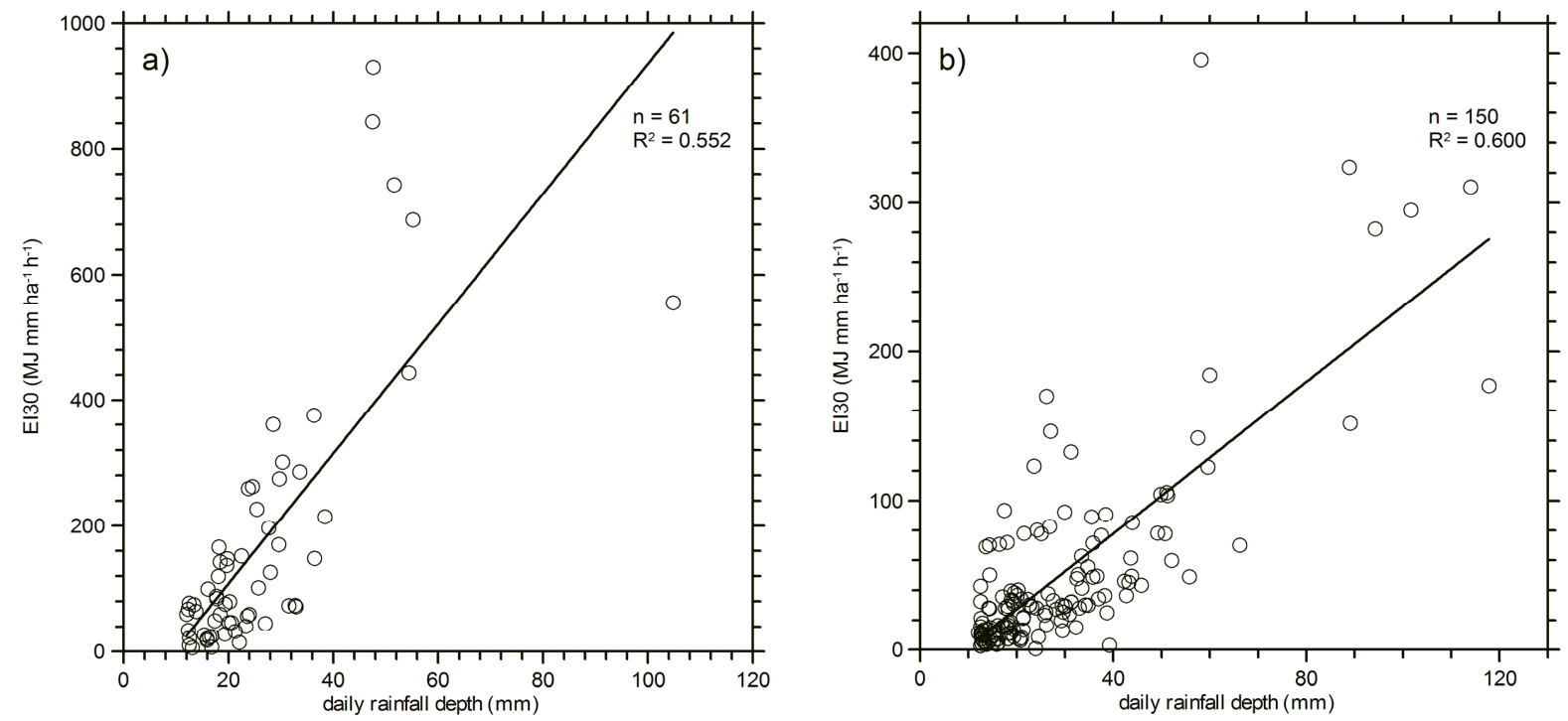

Fig. 5. Scatter plots of daily rainfall erosivity versus daily rainfall for the Vallcebre weather station: (a) summer and (b) rest of the seasons.

varied between years: coefficients of variations ranged between $12 \%$ and $66 \%$, with a mean value of $35 \%$. Nevertheless, spatial variability decreased when the inter-annual $R$ values were considered, as the coefficient of variation dropped to $18 \%$. This result may be seen as a consequence of the importance of summer rainstorms in the annual erosivity values. These storms are known to occur a few times every year but not at the same time at all stations, as they cover only a reduced area (Latron et al., 2003). In the long term, spatial variability is reduced because of the random spatial occurrence of storms.
The uncertainty of the long-term total $R$ value attributed to spatial variability was $125 \mathrm{MJ} \mathrm{mm} \mathrm{ha}^{-1} \mathrm{yr}^{-1}$ (6.4\% of the $R$ value), expressed in terms of the standard error of the mean because the stations were considered as nearly random observations of the average value, whose error would decrease with a denser rainfall recording network.

Temporal variability of the annual erosivity values at the stations was diverse, with variation coefficients between 33 and $52 \%$ and a weighted mean of $44 \%$.

The uncertainty of the long-term $R$ value attributed to temporal variability was $175 \mathrm{MJ} \mathrm{mm} \mathrm{ha}^{-1} \mathrm{yr}^{-1}$ (8.9\% of the 
Table 4. Variation coefficients (percent values) estimated for rainfall erosivity $\left(E I_{30}\right)$ and long-term erosivity $R$ factor, taking into account the diverse sources of uncertainty.

\begin{tabular}{|c|c|c|c|c|c|c|c|}
\hline & & instrument & kinetic energy & daily values & spatial & temporal & total \\
\hline single year $E I_{30}$ & single rain type & 4.5 & 10.7 & 3.0 & 6.4 & 43.7 & 45.8 \\
\hline single year $E I_{30}$ & diverse rain types & 4.5 & 2.2 & 3.0 & 6.4 & 43.7 & 44.6 \\
\hline long term $R$ & single rain type & 4.5 & 10.7 & 3.0 & 6.4 & 8.9 & 16.3 \\
\hline long term $R$ & diverse rain types & 4.5 & 2.2 & 3.0 & 6.4 & 8.9 & 12.4 \\
\hline
\end{tabular}

$R$ value), expressed in terms of the standard error of the mean.

\section{Summary and conclusions}

The above analysis shows that the roles of the diverse sources of uncertainty in the calculation of rainfall erosivity depend on the spatial and temporal scales considered.

It was also highlighted the need for identifying the systematic or random nature of errors, as only the second type of errors are gradually cancelled out when more observations are obtained. In this case, this was primarily relevant respect to the potential occurrence of diverse types of rain events. At the event scale we had to assume that any type of rain was possible and therefore a systematic nature of the errors estimated with Eq. (5) was associated to the kinetic energy for every time step of the events. For annual or a long-term period, the uncertainty largely decreased if the occurrence of diverse types of rain was assumed and a random nature of errors was therefore used.

When rainfall erosivity measurements were determined at the site and event scales, as are commonly needed for experimental or modelling purposes, instrument errors induced a coefficient of variation of up to $10 \%$, and the determination of kinetic energy from rainfall measurements induced a further coefficient of variation of about $30 \%$. These uncertainties depend much more on the methods used than on local factors, although the lower the rainfall intensity, the larger the uncertainty expected. Equation (5) may be used for estimating the uncertainty associated with the calculation of the rainfall kinetic energy from rainfall intensity with the Kinnell (1981) equation. Better estimates of event rainfall erosivity would need direct or indirect information on drop size distribution or kinetic energy during the events.

Table 4 shows the variation coefficients estimated for rainfall erosivity at the annual scale and the long-term erosivity $R$ factor at the long-term scale, taking into account the diverse sources of uncertainty investigated. When rainfall erosivity was determined at the scale of one year, temporal variability was the main source of uncertainty, whereas the calculation of rainfall kinetic energy from rainfall measurements was the second source of uncertainty when it cannot be assumed that there are diverse types of rain during the year. When the long-term $R$ factor was sought, the relative importance of these uncertainty sources was reversed.

Finally, these results show that the uncertainty associated with the estimation of rainfall kinetic energy and erosivity must be particularly taken into account when needed at the short temporal (event) scale, whereas for the basin scale, although spatial and temporal variability of the annual rainfall erosivity values was high, the averaging of 8 rainfall stations over 13 years was sufficient to afford a fair level of uncertainty in the long-term $R$ factor for the extension and climatic characteristics of the study area.

Acknowledgements. The research leading to these results has received funding from the European Community's Seventh Framework Programme (FP7/2007-2011) under grant agreement 211732 (MIRAGE project). The PROBASE (CGL2006-11619/HID) and MONTES (CSD2008-00040) projects, funded by the Spanish Government, also contributed to its development. Research at the Vallcebre catchments is also supported by the agreement (RESEL) between the CSIC and the "Ministerio de Medio Ambiente y Medio Rural y Marino" (Environment Ministry). The contribution of G. Catari was made possible by a DEBEQ grant, funded by the Autonomous Government of Catalonia. J. Latron was the beneficiary of a research contract (Ramón y Cajal programme) funded by the "Ministerio de Ciencia e Innovación" (Science Ministry). The authors are indebted to Montserrat Soler and Juliana Delgado and the other members of the Surface Hydrology and Erosion Research Group at IDAEA, CSIC for providing the necessary data and assistance. The authors are also grateful to M. Sivapalan and two anonymous referees whose questions and comments contributed to improving the paper.

Edited by: M. Sivapalan

\section{References}

Assouline, S. and Mualem, Y.: The similarity of regional rainfall: a dimensionless model of drop size distribution, T. ASAE, 32(4), 1216-1222, 1989.

Biesemans, J., Van Meirvenne, M., and Gabriels, D.: Extending the RUSLE with the Monte-Carlo error propagation technique to predict long-term average off-site sediment accumulation, J. Soil Water Conserv., 55(1), 35-42, 2000.

Brown, L. C. and Foster, G. R.: Storm erosivity using idealized intensity distributions, T. ASAE, 30, 379-386, 1987. 
Calder, I. R. and Kidd, C. H. R.: A note on the dynamic calibration of tipping-bucket gauges, J. Hydrol., 39, 383-386, 1978.

Catari, G.: Soil loss assessment in a medium sized basin in the SE Pyrenees, Ph.D. Thesis, Autonomous University of Barcelona, Barcelona, Spain, 2010.

Catari, G. and Gallart, F.: Rainfall erosivity in the upper Llobregat basin, SE Pyrenees, Pirineos, 165, 55-67, 2010.

Ciach, G. J.: Local random errors in Tipping-bucket rain gauge measurements, J. Atmos. Ocean. Tech., 20, 752-759, 2003.

de Santos Loureiro, N. and de Azevedo Couthino, M.: A new procedure to estimate the RUSLE EI30 index based on monthly rainfall data applied to the Algarve region, Portugal, J. Hydrol., 250, 12-18, 2001.

Delgado, J. M.: Análisis de series hidrológicas y climáticas para su aplicación en el estudio de los efectos del cambio de uso del suelo sobre el balance hídrico en la cabecera del Llobregat, M.Sc. thesis, Autonomous University of Barcelona, Barcelona, Spain, 2006.

Diodato, N.: Estimating RUSLE's rainfall factor in the part of Italy with a Mediterranean rainfall regime, Hydrol. Earth Syst. Sci., 8, 103-107, doi:10.5194/hess-8-103-2004, 2004.

Falk, M. G., Denham, R. J., and Mengersen, K. L.: Estimating Uncertainty in the Revised Universal Soil Loss Equation via Bayesian Melding, J. Agr. Biol. Envir. St., 15(1), 20, 2010.

Foster, G. R.: Revised Universal Soil Loss Equation Version 2: User reference guide, USDA Natural Resources Conservation Service, Tennessee, 2004.

Gallart, F., Llorens, P., Latron, J., and Regüés, D.: Hydrological processes and their seasonal controls in a small Mediterranean mountain catchment in the Pyrenees, Hydrol. Earth Syst. Sci., 6, 527-537, doi:10.5194/hess-6-527-2002, 2002.

Hartcher, M. and Post, D.: Reducing uncertainty in sediment yield through improved representation of land cover: application to two sub-catchments of the Mae Chaem, Thailand, in: MODSIM 2005 International Congress on Modelling and Simulation, 12-15 December 2005, edited by: Zerger, A. and Argent, R., Modelling and Simulation Society of Australia and New Zealand, 1147-1153, 2005.

Hudson, N. W.: An introduction to the mechanics of soil erosion under conditions of subtropical rainfall, Proc. Trans. Rhod. Sci. Assoc., 49, 14-25, 1961.

INM - Instituto Nacional de Meteorología: Series de precipitación, Madrid, Spain, 2004.

Joss, J. and Waldvogel, A.: Ein Spektrograph für Niederschlagstrophen mit automatischer Auswertung, Pure Appl. Geophys., 68, 240-246, 1967.

Kinnell, P. I. A.: The problem of assessing the erosive power of rainfall from meteorological observations, Soil Sci. Soc. Am. J., 37, 617-621, 1973.

Kinnel, P. I. A.: Rainfall intensity-kinetic energy relationships for soil loss prediction, Soil Sci. Soc. Am. J., 45, 153-155, 1981.

Latron, J., Anderton, S., White, S., Llorens, P. and Gallart, F.: Seasonal characteristics of the hydrological response in a Mediterranean mountain research catchment (Vallcebre, Catalan Pyrenees): field investigations and modelling, in: Hydrology of Mediterranean and Semiarid Regions, edited by: Servat, E., Najem, W., Leduc, C., and Shakeel, A., IAHS pub. no. 278, 106110,2003

Latron, J., Llorens, P., Soler, M., Poyatos, R., Rubio, C., Muzylo,
A., Martinez-Carreras, N., Delgado, M. J., Catari, G., Nord, G., and Gallart, F.: Hydrology in a Mediterranean mountain environment-The Vallcebre research basins (North Eastern Spain), I. 20 years of investigations of hydrological dynamics. Status and Perspectives of Hydrology in Small Basins, IAHS Publ. no. 336, 38-46, 2010.

Laws, J. O. and Parsons, D. A.: The relation of raindrop size to intensity, T. Am. Geophys. Un., 24, 452-460, 1943.

Marshall, J. S. and Palmer, W. M.: The distribution of raindrops with size, J. Meteorol., 5, 165-166, 1948.

McGregor, K. C., Bingner, R. L., Bowie, A. J., and Foster, G. R.: Erosivity index values for northern Mississippi, T. ASAE, 38(4), 1039-1047, 1995.

McGregor, K. L. and Mutchler, C. V.: Status of the $R$ factor in Northern Mississippi, Soil Erosion: Prediction and Control, Soil Conservation Service, US Department of Agriculture, Washington, DC, 135-142, 1976.

MMA - Ministerio de Medio Ambiente: Inventario nacional de erosión de suelos 2002-2012, Provincia Barcelona, Cataluña, Dirección de Biodiversidad, 2004.

Moulin, L., Gaume, E., and Obled, C.: Uncertainties on mean areal precipitation: assessment and impact on streamflow simulations, Hydrol. Earth Syst. Sci., 13, 99-114, doi:10.5194/hess-13-992009, 2009.

Parsons, A. J. and Gadian, A. M.: Uncertainty in modelling the detachment of soil by rainfall, Earth Surf. Proc. Land., 25(7), 723-728, 2000.

Rosewell, C. J.: Rainfall kinetic energy in Eastern Australia, J. Clim. Appl. Meteorol., 25, 1695-1701, 1986.

Salles, C., Poesen, J., and Sempere-Torres, D.: Kinetic energy of rain and its functional relationship with intensity, J. Hydrol., 257(1-4), 256-270, 2002.

Sempere Torres, D., Porrà, J. M., and Creutin, J. D.: A general formulation for rain Drop Size Distribution, J. Appl. Meteorol., 33, 1494-1502, 1994.

Sevruk, B.: Point precipitation measurements: why are they not corrected?, in: water for the Future, IAHS Publ. no. 164, 477486, 1987.

Thiessen, A. H.: Precipitation averages for large areas, Mon. Weather Rev., 39, 1082-1084. 1911.

Usón, A. and Ramos, M. C.: An improved rainfall erosivity index obtained from experimental interrill soil losses in soils with a Mediterranean climate, Catena, 43, 293-305, 2001.

van Dijk, A. I. J. M., Bruijnzeel, L. A., and Rosewell, C. J.: Rainfall intensity-kinetic energy relationships: a critical literature appraisal, J. Hydrol., 261, 1-23, 2002.

Wang, G., Gertner, G., Parysow, P., and Anderson, A.: Spatial prediction and uncertainty assessment of topographic factor for revised universal soil loss equation using digital elevation model, ISPRS J. Photogramm., 56, 65-80, 2001.

Wischmeier, W. H. and Smith, D. D.: A rainfall erosion index for a universal soil loss equation, Soil. Sci. Soc. Am. Proc., 23, 246249, 1959.

Wischmeier, W. H. and Smith, D. D.: Predicting Rainfall Erosion Losses: A guide to conservation planning, U. S. D. A. Agriculture Handbook, Washington, DC, 537, 1978.

Zawadzki, I. and Antonio, M. D. A.: Equilibrium raindrop size distributions in tropical rain, J. Atmos. Sci., 45(22), 3452-3460, 1988. 